\title{
Stated Preference surveys and the valuation of urban transport systems
}

\author{
S. Basbas \\ Department of Transportation and Hydraulic Engineering, \\ Faculty of Rural and Surveying Engineering, School of Technology, \\ Aristotle University of Thessaloniki, Greece
}

\begin{abstract}
Stated Preference (SP) surveys are widely used in the transport sector as far as the investigation of travel behaviour and demand modelling is concerned. Results from SP surveys that were carried out in the city of Thessaloniki, Greece, for various transport projects are presented in the framework of this paper. More specifically, these results concern the metro system, the submerged tunnel, the sea transport system, a modern technology parking station (stated and revealed preference survey) and a bus passenger information system. The willingness-topay values are also presented in this paper. It is concluded that the use of SP surveys provides valuable information in the planning process for an efficient transport system.
\end{abstract}

Keywords: Stated Preference (SP), willingness-to-pay, valuation, public transport, metro, submerged tunnel.

\section{Introduction}

It is essential for authorities, organisations, and companies that take decisions concerning transport projects or policies, to know and understand the way individuals make their trip choices. Stated Preference (SP) surveys have been used worldwide in recent decades in order to allow individuals to make a choice between various alternatives in the transport sector (e.g., different transport modes). The use of SP surveys can nowadays be accepted "as a logical approach to extending the behavioural response space for studies of traveler behaviour and travel demand" [1]. It must be mentioned that SP surveys play an important role in the development of a sustainable urban transportation system [2]. There are 
many studies all over the world where SP surveys have been used. For example, individual preferences for different cycling facilities are analysed by using an adaptive stated preference (ASP) survey [3], perceptions and preferences of passengers on interurban bus and rail routes in Ireland are collected by both stated and revealed preference survey [4], the evaluation of statistical life for interurban motorways in Chile was valuated with the use of an SP survey [5], the environmental problems associated to urban traffic in Norway are valuated with the use of Stated Choice survey (attributes are assessed relatively to each other) [6] and the estimation of preferences of logistics managers in Italy for freight service attributes (cost, travel time, punctuality, damage and loss) is made by using an adaptive conjoint analysis (ACA) [7]. Within the framework of this paper, results from SP surveys that were carried out in the city of Thessaloniki, Greece, for various transport projects are presented. These results concern the metro system, the submerged tunnel, the sea transport system, a modern technology parking station (stated and revealed preference survey) and a bus passenger information system. The willingness-to-pay values are also presented in this paper.

\section{Stated preference surveys in the city of Thessaloniki}

The results of SP surveys that were conducted in the framework of various transport studies in the city of Thessaloniki are presented hereinafter. Thessaloniki is the second biggest city in Greece, is situated in the north part of the country and has a population of around one million inhabitants. A number of 1.600.00 trips were made in 1998 on a daily basis in the city with all transport modes (compared to 1.350 .000 in the year 1988) of which 400.000 trips had at least one end in the city centre $[8,9]$. The car ownership (number of passenger cars per 1.000 inhabitants) varies between 220 and 305 with an average value of 253, while ten years before the respective value was 177 . According to the results of the traffic simulation model EMME/2, which was used in the framework of the Thessaloniki General Transportation Study, this figure will be in the area of 428 to 440 in the year 2014 [9]. The Public Transport (PT) system in the city consists only of buses. More specifically, the Thessaloniki Bus Operator (O.A.S.Th.) has a total number of 583 buses [10]. There are 72 bus lines carrying around 150 million passengers per year. It must be mentioned that the city is characterized by serious traffic and associated environmental problems especially in its centre. This is the reason why major transport infrastructure projects are under construction (i.e. metro) or are expected to be constructed (i.e. submerged tunnel).

\section{Thessaloniki General Transportation Study}

An SP home-based survey was conducted in the framework of the Thessaloniki General Transportation Study in 1999 [9]. The aim of the specific survey was to investigate the behaviour of citizens as far as their trip characteristics are concerned. Four discrete categories of the population are considered for the purposes of the SP survey as follows: 
1. Citizens, living in the city centre, who they exclusively use Public Transport.

2. Citizens, living outside the city centre, who they exclusively use Public Transport.

3. Citizens, living in the city centre, who they use both PT and private cars (but they are basically considered as private cars users).

4. Citizens, living outside the city centre, who they use both PT and private cars (but they are basically considered as private cars users).

Six types of games using specific printed coloured cards were used in the survey. A total of 900 questionnaires were collected, covering all four categories of the population as follows: 150 questionnaires from category 1, 300 questionnaires from category 2, 150 questionnaires from category 3 and finally, 300 questionnaires from category 4. The statistical software SPSS was used for the purposes of the data processing and analysis. It is interesting to focus on the Willingness-To-Pay (WTP) more expensive PT fares in return for a reduced travel time (Table 1).

Table 1: $\quad$ WTP expensive fares in return for reduced travel time with PT.

\begin{tabular}{|c|c|c|c|c|}
\hline \multirow[b]{2}{*}{ Travel time } & \multicolumn{4}{|c|}{ WTP Public Transport fares } \\
\hline & 0,73 euros & 0,59 euros & 0,44 euros & $\begin{array}{c}0,29 \text { euros } \\
\text { (existing } \\
\text { fare) }\end{array}$ \\
\hline $\begin{array}{l}\text { Reduction to } 2 / 3 \text { of the } \\
\text { original travel time }\end{array}$ & $5,9 \%$ & $12,5 \%$ & $36,9 \%$ & $44,7 \%$ \\
\hline $\begin{array}{l}\text { Reduction to } 1 / 2 \text { of the } \\
\text { original travel time }\end{array}$ & $15,5 \%$ & $32,1 \%$ & $33,8 \%$ & $18,6 \%$ \\
\hline
\end{tabular}

Source: [9]

As shown in Table 1, quite a lot of people $(44,7 \%)$ are not prepared to pay high fares in order to experience significant benefits of travel time (2/3 of the original travel time) with the PT system. Even in the case of very significant benefits $(1 / 2$ of the original travel time), people are still reluctant to a great extent $(18,6 \%)$ to pay high fares. It must be mentioned at this point that reduced travel time can be mainly achieved through the implementation of bus lanes in the city network. There are four with-flow bus lanes in the city road network, three of which are found in the central area (Mitropoleos Str., Tsimiski Str., Egnatia Str.) and one in the eastern part of the city (V.Olgas Str.). Although the benefits in term of bus speed were very significant immediately after the implementation of the bus lanes, these benefits tend to be decreased nowadays due to the bus lane violations [11]. Another important finding of the SP survey has to do with the WTP in relation to the income of the respondents and also their category (PT users, private car users). These results show that people belonging to categories 3 and 4 (basically considered as private cars users) are, in general, willing to pay much higher fares (0,59 to 0,73 euros) in order to benefit from reduced travel time with PT. This can be partially explained by the fact that these people rarely use PT and at the same time they pay quite a lot of money to 
travel in their private cars, so that they can afford the high cost of the ticket to a certain extent. The level of the personal income also affects people's decisions to pay high fares, as it was expected, something which is clearly presented when the fare of 0,73 euros is examined for both PT users and private car users (this fare corresponds to high income groups).

\section{Metro system}

An important on-going project in Thessaloniki concerns the construction of a metro system. The technical characteristics of this system are the following: basic line with a length of 9,6 km. (two tunnels, single track), 13 stations, designed capacity of 18.000 passengers/hour/direction, estimated number of passengers equal to $250.000 /$ day) [12]. The first line of $9,6 \mathrm{~km}$. length is expected to finish by the year 2012. Two other lines are also foreseen in the long term: the first line will have a length of $5,8 \mathrm{~km}$. and it will serve the western part of the city and the second line will have a length of $5 \mathrm{~km}$. and will serve the eastern part of the city. The estimated cost of the basic line is 1.060 million euros while the cost of the additional two lines is estimated to be 1.100 million euros. An SP survey for the metro system was conducted in the framework of the Aristotle University research activities [13] in 2006. The aim of the survey was to examine people's intentions for trips by metro, their WTP for the new system etc. The survey was carried out in the city centre during September and October of 2005 and 400 questionnaires were collected in total. Some of the most important results are presented in Figures 1,2 and 3. Figure 1 presents the fares which people are willing to pay for using the metro system. The majority of people $(47,6 \%)$ are willing to pay 0,50 euros for their trips by metro, which is actually the same with the existing fares of the PT buses.

Figure 2 presents the WTP distribution among categories of potential metro system users with different personal monthly income. People with high income are willing to pay more expensive fares $(0,70-1,0$ euros compared to the existing bus fares of 0,50 euros) as it is expected.

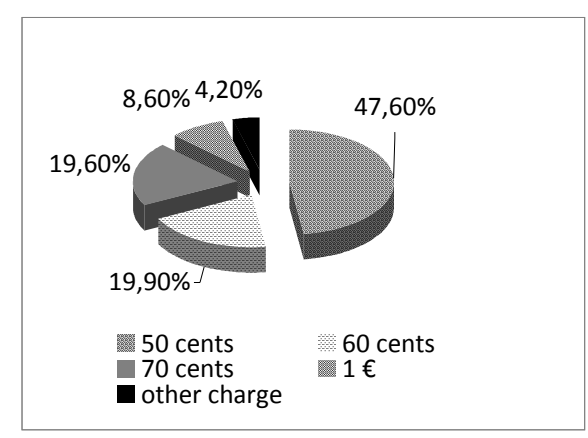

Figure 1: WTP for the metro system. 


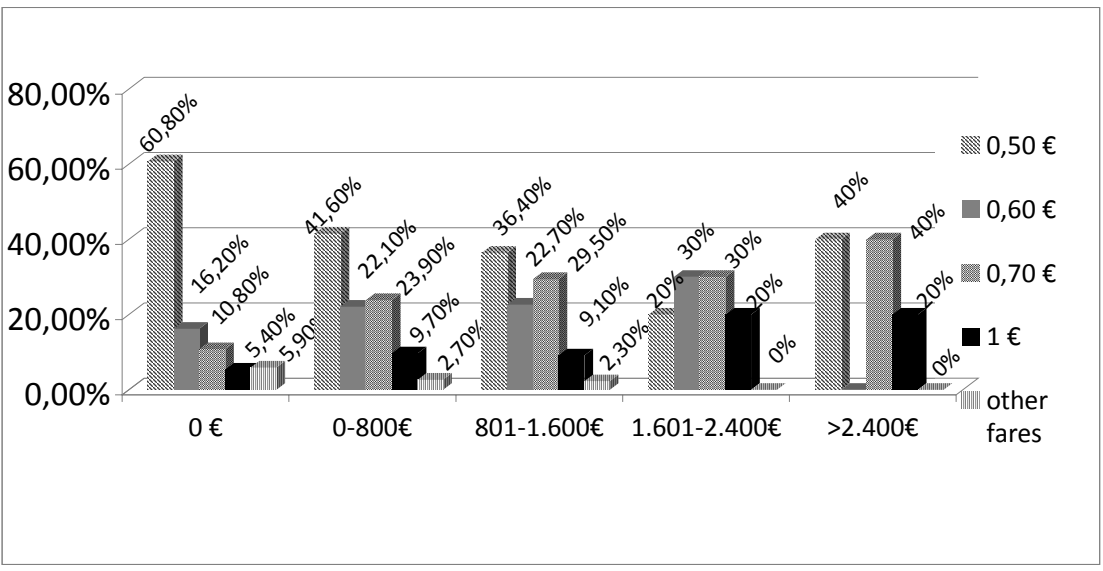

Figure 2: $\quad$ WTP distribution and monthly income for potential metro system users.

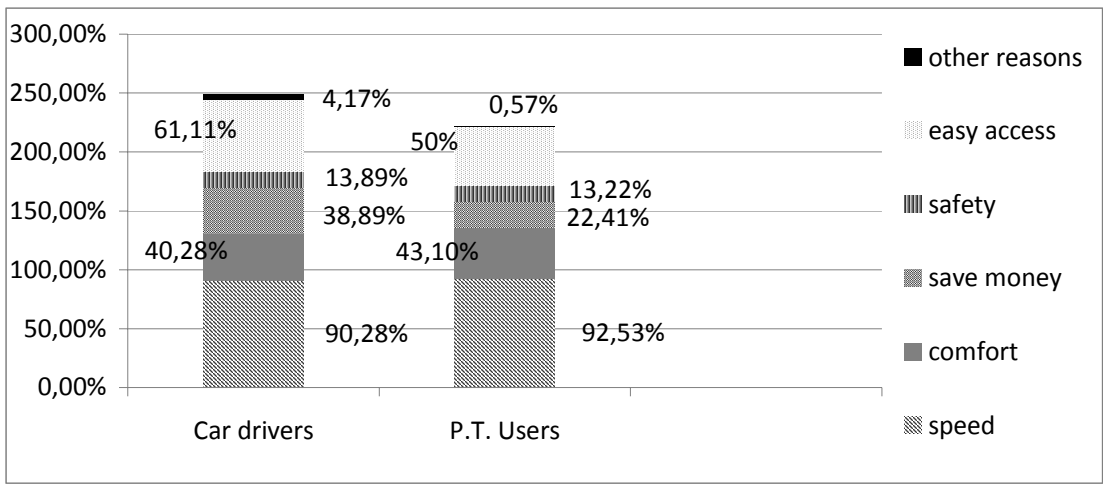

Figure 3: Reasons for the selection of the metro system.

Figure 3 presents the main reasons why car drivers and PT (buses) users are willing to choose the metro for their trips. The majority of the respondents choose the metro for better speed and easy access to their destinations.

\section{University students and the Public Transport System}

The impact of the metro system to the students of the Aristotle University of Thessaloniki is examined in the framework of another SP survey. This survey was carried out in the framework of the Aristotle University research activities [14] in 2007. The basic line of the metro system will pass the University campus, which is situated in the perimeter of the city centre and two metro stations are foreseen to serve the specific area. The objective of the SP survey was the 
investigation of the University students' choices and preferences concerning the existing PT system (buses) and the new system (metro). The survey was carried out from May to June 2007 in the University campus and 294 questionnaires were collected and analyzed. Data collected include socioeconomic characteristics of the students, their trip characteristics, their preferences and choices for the PT system etc. One of the most interesting results concerns fares that students are willing to pay in order to use metro for their trips (Figure 4). The majority of students (44\%) are willing to pay 0,50 euros (same as existing bus fares) and $41 \% 0,25$ euros.

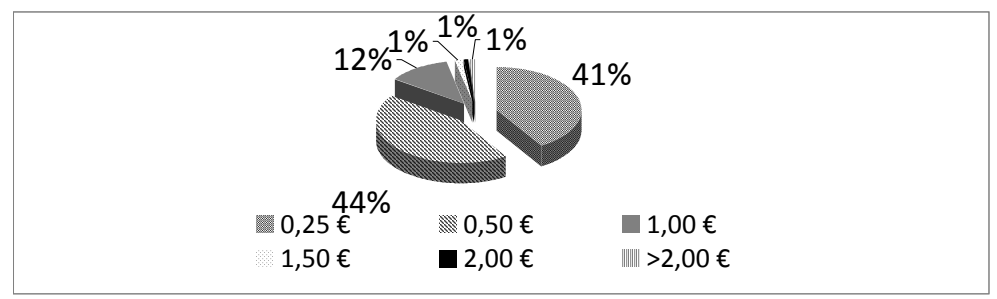

Figure 4: WTP of the University students for the metro system.

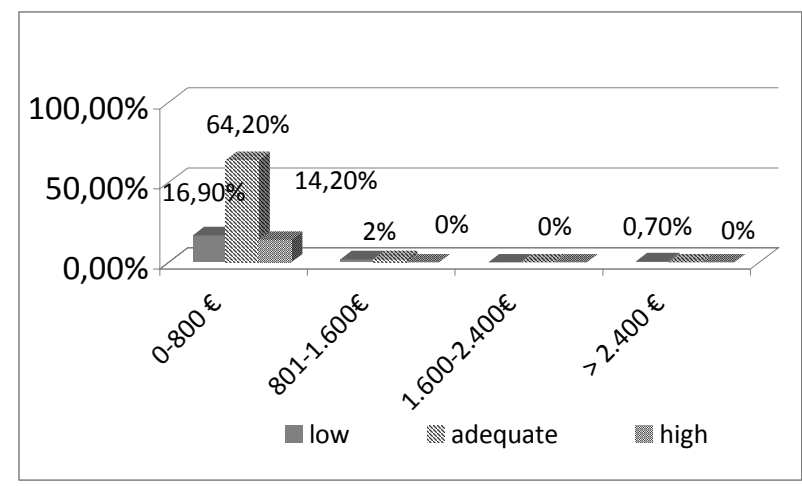

Figure 5: Consideration of existing bus fares by the University students according to their monthly income.

Figure 5 presents the results concerning respondents' opinions about the existing PT (buses) fares (0,50 euros) in relation to their personal monthly income. University students whose income is $0-800$ euros per month believe that bus fares are high.

\section{Submerged tunnel}

An important on-going project in Thessaloniki is the construction of a submerged tunnel that aims at enabling through traffic to bypass the city centre 
[15]. The proposed design according to the preliminary design study connects the western main entrance of the city with the eastern part of the city. The main body of the arterial has a total length of approximately $3950 \mathrm{~m}$. It consists of three lanes per direction and has one entrance/exit from the east and two entrances/exits from the west. An additional entrance will be available from the north-east. According to the design studies the submerged tunnel is proposed to be used only by passenger vehicles, buses and trucks of gross weight up to 4.0 tons [16]. The submerged tunnel will have both positive traffic and environmental effect on the city. According to the results of the use of the traffic simulation model SATURN, an average increase in the speed of cars by $35 \%$ is foreseen during peak hours for the basic road network.

From May to June 2003 an SP survey was conducted on behalf of the Ministry for the Environment, Physical Planning and Public Works, in order to capture the preferences and choices of the potential users of the tunnel [16]. In total 1132 questionnaires were collected of which 946 were considered valid. The majority of potential users $(50,6 \%)$ declare willingness to use the submerged tunnel and be charged, while $38,3 \%$ state that they will use the alternative surface route. The percentage of those who were undecided was $11,1 \%$.

In the framework of another SP survey [17] for the same project, which was conducted in 1999, 295 questionnaires were collected. These questionnaires referred to private car users only. According to the results of the specific survey a percentage of $61 \%$ declare willingness to use the submerged tunnel and be charged, while $39 \%$ state that they will use the alternative surface route. The analysis of WTP for different time gain is presented in Table 2. Results show that drivers are willing to pay more for significant time gain. The interviewees' perceived value of time per trip purpose that resulted for the two surveys is shown in Table 3.

Table 2: $\quad$ WTP for different time gains.

\begin{tabular}{|l|c|c|c|}
\hline Time gain & $\begin{array}{c}\text { \% of respondents } \\
\text { willing to pay }\end{array}$ & $\begin{array}{c}\text { Payment range } \\
\text { (in euros) }\end{array}$ & $\begin{array}{c}\text { Average payment } \\
\text { (in euros) }\end{array}$ \\
\hline $10 \mathrm{~min}$. & $80 \%$ & $0.03-1.47$ & 0.37 \\
\hline $20 \mathrm{~min}$. & $94 \%$ & $0.15-1.47$ & 0.56 \\
\hline $40 \mathrm{~min}$. & $97 \%$ & $0.15-5.87$ & 0.91 \\
\hline
\end{tabular}

Source: $[16,17]$

Table 3: $\quad$ Perceived value of time per trip purpose.

\begin{tabular}{|l|c|c|c|c|}
\hline Trip purpose & \multicolumn{2}{|c|}{$\begin{array}{c}\text { Value of time } \\
\text { (euros/hour) }\end{array}$} & \multicolumn{2}{c|}{$\begin{array}{c}\text { Value of time } \\
\text { (euros/min) }\end{array}$} \\
\hline & Year 2003 & Year 1999 & Year 2003 & Year 1999 \\
\hline From/to work or school & 3,18 & 2,28 & 0,053 & 0,038 \\
\hline Business & 2,88 & - & 0,048 & - \\
\hline Other purposes & 2,44 & 1,29 & 0,041 & 0,022 \\
\hline
\end{tabular}

Source: $[16,17]$ 


\section{Sea transport}

Sea transport linking adjacent coastal areas has also been proposed in order to bypass the congested arterials connecting the city centre with the eastern suburbs [18]. The Organization for the Master Plan and Environmental Protection of Thessaloniki launched a call for proposals in 1995 for those who are, in principal, interested to operate such a service. Services would be provided by $7-$ 8 catamarans, which can carry up to 250 seated passengers each [19]. The travel time will be reduced by $50 \%$ when compared to the existing travel time by bus and by $30 \%$ when compared to the existing travel time by private car (for the same origin-destination route). With this project a reduction of average travel time by $50 \%$ would be achieved compared to respective time of buses and by $30 \%$ compared to the respective time of passenger cars. The results of an SP survey which was conducted in 2003 [19], including systematic PT users (85\%) and non-systematic PT users (15\%) show that sea transport would attract $62 \%$ of the non-systematic PT users and 77\% of the systematic PT users, mainly for the trip purpose 'work', on the condition that travel time benefits will exist. The total number of questionnaires that was finally analysed was 475 . It must be mentioned at this point that traffic model forecasts show that the annual number of passengers will be in the area of 5.100.000 to 10.800 .000 depending on the number of stops and the frequency. The WTP, as far as the potential users of sea transport are concerned, is presented in Table 4. As it was highly expected, people are willing to pay more money for considerable travel time gain (i.e. reduction of travel time by $50 \%$ ).

Table 4: $\quad$ WTP in return for reduced travel time with the sea transport.

\begin{tabular}{|l|c|c|c|}
\hline WTP & $\begin{array}{c}\text { Reduction of } \\
\text { travel time by } \\
10 \%\end{array}$ & $\begin{array}{c}\text { Reduction of } \\
\text { travel time by } \\
30 \%\end{array}$ & $\begin{array}{c}\text { Reduction of } \\
\text { travel time by } \\
50 \%\end{array}$ \\
\hline $\begin{array}{l}0,45 \text { euros } \\
\text { (existing fare of } \\
\text { PT bus) }\end{array}$ & $13 \%$ & $11 \%$ & $15 \%$ \\
\hline 0,65 euros & $7 \%$ & $7 \%$ & $10 \%$ \\
\hline 0,90 euros & $2 \%$ & $6 \%$ & $10 \%$ \\
\hline 1,35 euros & $3 \%$ & $5 \%$ & $9 \%$ \\
\hline$>1,35$ euros & $1 \%$ & $0 \%$ & $1 \%$ \\
\hline
\end{tabular}

Source: [19]

\section{Modern technology parking station}

A modern technology parking station (Y.M.C.A. parking station) was constructed in 2004 in the eastern part of the Thessaloniki city centre. The station has 958 parking places where parking is made without the involvement of the station personnel and 63 "conventional type" parking places. An SP and Revealed Preference (RP) survey was carried out in the framework of the 
Aristotle University research activities [20] in 2006 in order to investigate the choices and preferences of the parking station users, regarding the modern technology used in the station. A total number of 300 questionnaires were collected in this survey. Figure 6 presents the way the users evaluate (in terms of monetary values - they have been asked to allocate one euro) the specific services of the station. The automatic parking is the most important service according to the users.

Figure 7 presents how different age groups evaluate the services. As it is presented in Figure 7 people equal to or older than 65 years old consider the automatic parking as the most important service in the parking station (they allocated 0,67 euros out of one euro they have to spent).

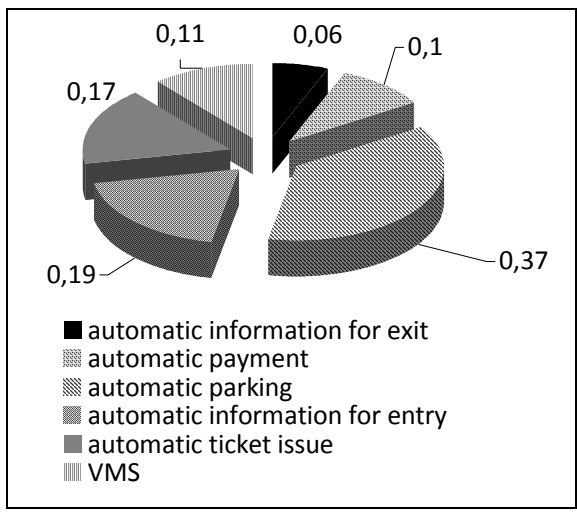

Figure 6: Evaluation by the users of the services provided in the parking station.

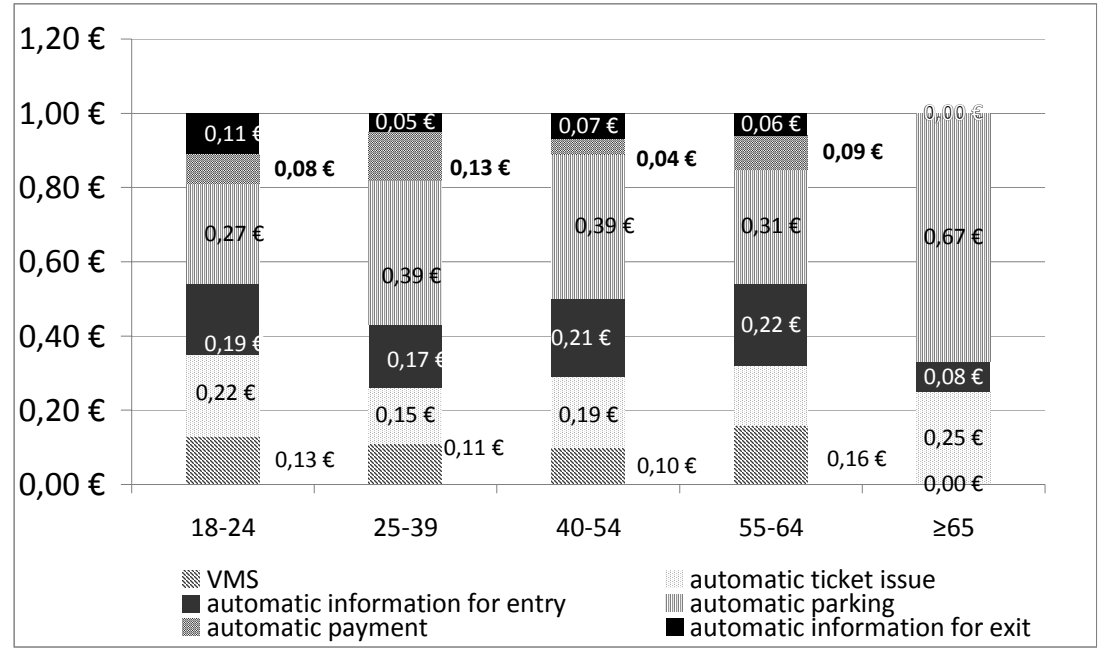

Figure 7: Cost estimation from different age groups. 


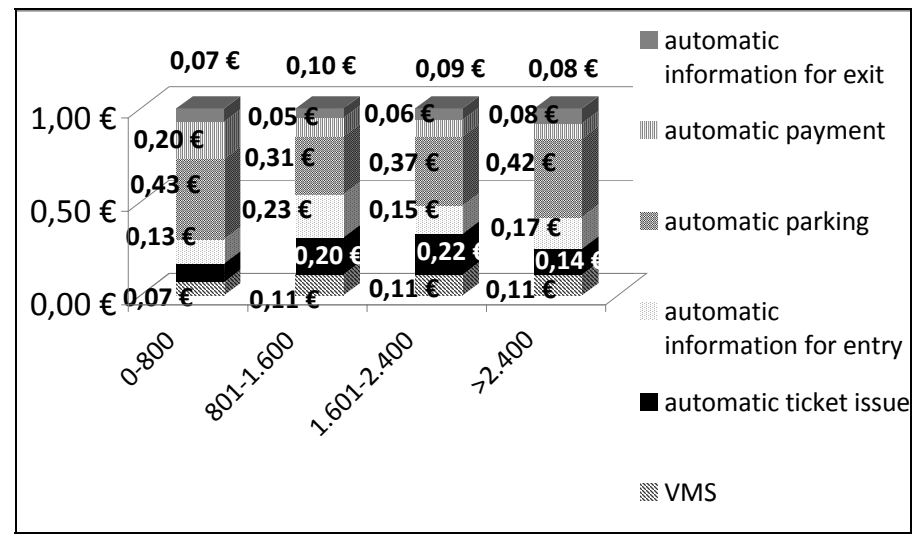

Figure 8: Cost estimation from different income groups.

Figure 8 presents the way users of different personal monthly income evaluate the services. As it is presented in Figure 8 people (irrespectively of their income) are willing to pay more for automatic parking with highest values of 0,42 euros and 0,43 euros.

\section{Passenger information system}

A passenger information system was designed for the Thessaloniki Bus Operator in the early ' $90 \mathrm{~s}$ within the framework of the EU project EUROBUS/POPINS [15]. In the framework of this project the design and development of an interactive passenger information terminal was made. The system was called Thessaloniki Passenger Information System (THEPIS) having as its main objective the provision of information in an interactive way to bus passengers $[21,22]$. The information provided, refers to the bus network, schedules, places of public interest etc. THEPIS would initially provide "off-line" information (i.e. bus schedules) but it could be converted to a real time information system when the appropriate infrastructure would be available. The THEPIS comprised a central processing unit, a geographical database containing information about the city, a number of external data bases retaining information about the bus network, and one (or more) terminal - with or without keyboards - displaying the information.

An SP survey based evaluation of THEPIS was conducted in the city prior to the test implementation of the system [23]. A number of 170 potential THEPIS users were interviewed and 148 valid questionnaires were retained for further analysis. Two target groups were interviewed including PT users and non PT users (passenger cars and taxi users). In terms of mode choice and assuming that there will be no difference in journey time between car/taxi and bus for the same trip and no change in bus fare, it is estimated that $3 \%$ of the existing car and taxi users would switch to the bus if THEPIS was available. For a 5-min advantage of the bus trip against the equivalent car/taxi journey time, the proportion of existing car/taxi users that will switch to the bus (with THEPIS) is estimated at $21 \%$. 


\section{Conclusions}

The use of SP surveys for different transport modes (e.g., metro, buses) or for different transport infrastructure (e.g., submerged tunnel, parking station) in Thessaloniki offered valuable information about the way people make their trip choices. Especially the WTP data will assist the formation of the most adequate pricing policy, so that the under examination transport projects will be economically viable. Although the final decision about the construction of transport infrastructure or the implementation of transport demand policies does not exclusively depend on the SP results, it is considered as a necessary step to conduct such surveys in the framework of feasibility studies.

\section{References}

[1] Hensher, D.A., Stated preference analysis of travel choices: the state of practice, Transportation, 21, Kluwer Academic Publishers, pp. 107-133, 1994.

[2] Loo, B.P.Y., Role of Stated Preference Methods in Planning for Sustainable Urban Transportation: State of Practice and Future Prospects, Journal of Urban Planning and Development, pp. 210-224, 2002.

[3] Tilahun, N.Y., Levinson, D.M. \& Krizek, K.J., Trails, lanes, or traffic: valuing bicycle facilities with an adaptive stated preference survey, Transportation Research Part A, 41, Elsevier, pp. 287-301, 2007.

[4] Ahern, A.A. \& Tapley, N., The use of stated preference techniques to model choices on interurban trips in Ireland, Transportation Research Part A, 42, Elsevier, pp. 15-27, 2008.

[5] Rizzi, L.I. \& Ortuzar, J. de D., Stated preference in the valuation of interurban road safety, Accident Analysis and Prevention, 35, Pergamon, pp. 9-22, 2003.

[6] Sælensminde, K., Stated choice valuation of urban traffic air pollution and noise, Transportation Research Part D, 4, Pergamon, pp. 13-27, 1999.

[7] Danielis, R., Marcucci, E. \& Rotaris, L., Logistics managers' stated preferences for freight service attributes, Transportation Research Part E, 41, Elsevier, pp. 201-215, 2005.

[8] Laboratory of Transport Engineering, Faculty of Civil Engineering, Aristotle University of Thessaloniki, Research on trip characteristics in Thessaloniki Metropolitan Area, Thessaloniki, 1989.

[9] Denco, Trademco, I. Aggelidis, Truth, Infodim, WS-Atkins, Steer Davies Gleave, Thessaloniki General Transportation Study, Elaboration and analysis of the SP survey results, Organization for the Master Plan and Environmental Protection of Thessaloniki, Thessaloniki, June 1999.

[10] Urban Transport Organisation of Thessaloniki (OASTH), www.oasth.gr

[11] Basbas S., Examination of the bus lane enforcement system in Thessaloniki, Proc. of the $13^{\text {th }}$ International Conference on Urban Transport and the Environment in the 21st Century, ed. C.A. Brebbia, WIT Press, pp.25-34, 2007. 
[12] Attiko Metro S.A., www.ametro.gr

[13] Karamarkos, D., Stated Preference Survey for the Thessaloniki Metro, M.Sc Thesis, Supervisor: S. Basbas, Postgraduate Course on Organisation and Management of Resources and Development Works, Faculty of Rural and Surveying Engineering, Aristotle University of Thessaloniki, 2006.

[14] Tsiberidou, K., Evaluation of the level of service of Public Transport with reference to the Aristotle University of Thessaloniki, M.Sc Thesis, Supervisor: S. Basbas, Postgraduate Course on Planning, Organisation, and Management of Transport Systems, Aristotle University of Thessaloniki Hellenic Institute of Transport, 2007.

[15] Basbas S., Mintsis G. \& Taxiltaris C., Development of an integrated transportation system in Thessaloniki: current situation and future prospects (Chapter 8), Advances in City Transport: Case Studies, ed. S. Basbas, WIT Press: Southampton and Boston, pp.159-193, 2005

[16] TRIAS, Gregoriadou, M., Thessaloniki Submerged Tunnel - Stated Preference Survey, Final Report, Special Service of Public Works/Concession Road Arterials, General Secretariat of Public Works, Ministry for the Environment, Physical Planning and Public Works, 2003.

[17] TRIAS, Feasibility Study for the Thessaloniki Submerged Tunnel, ETEBA, 1999.

[18] Toskas, G., Urban sea transport in Thessaloniki, Organization for the Master Plan and Environmental Protection of Thessaloniki. Internal Report, 1999.

[19] Secretariat of Public Works, Region of Central Macedonia, Traffic Study of the urban sea transport in Thessaloniki. Technical Advisor: TRUTh, Final Report, Thessaloniki, 2003.

[20] Tsapikidis, I., Investigation of opinions and preferences of modern technology parking stations: the case of the YMCA parking station, M.Sc Thesis, Supervisor: S. Basbas, Postgraduate Course on Organisation and Management of Resources and Development Works, Faculty of Rural and Surveying Engineering, Aristotle University of Thessaloniki, 2007.

[21] Papaioannou, P., Basbas, S. \& Panayotakopoulos, P., A passenger information terminal for public transport in Thessaloniki. Proc. of the Int. Conf. on Advanced Technologies in Transportation and Traffic Management, Centre for Transportation Studies \& Centre for Continuing Education, Nanyang Technological University, pp. 359-366, 1994.

[22] Papaioannou, P., Basbas, S. \& Panayotakopoulos, P., The use of GIS technology in the development of an interactive passenger information terminal: the EuroBus Project. Proc. of the $6^{\text {th }}$ Canadian Conference on Geographic Information Systems, Surveys, Mapping and Remote Sensing Sector, Vol.1, pp. 478-488, 1994.

[23] Papaioannou, P., Basbas, S. \& Vougioukas, M., The use of stated preference technique in evaluating a passenger information system: the EuroBus/Popins/Thepis experience. Proc. of the 24th PTRC European Transport Forum, Vol. P 405, 1996. 